\title{
Study and Application on Risk Assessment Method of Coal Worker Pneumoconiosis Based on Logistic Regression Model ${ }^{*}$
}

\author{
Qian Zhang, Deyin Huang, Minyan Li \\ Institute of Occupational Health, Tianjin Bohai Chemical Industry Group Co. Ltd, Tianjin 300051, China
}

Received August 18, 2018

Accepted September 8, 2018

\begin{abstract}
To research the risk assessment method of coal-worker's pneumoconiosis caused by coal dust exposure, predict the incidence of coal-worker's pneumoconiosis, and provide technical basis for occupational risk management. Coal-workers of a coal transportation workshop of a heat power station were chosen as objectives. The incidence of coal-worker's pneumoconiosis was predicted by logistic non-linear regression model using the concentrations of the respirable coal dust that the workers exposed to and their exposure durations. Furthermore, a practical table of the relationship between the incidence probability of coal-worker's pneumoconiosis and exposure situation was created by using $\mathrm{R}$ programming language. It was found that if these coal workers exposed to the respirable coal dust of the current concentration for 5 or 10 years, the risk of coal-worker's pneumoconiosis would be between $10^{-5}$ and $10^{-6}$, and for 20 or 30 years, it would be between $10^{-3}$ and $10^{-2}$. Assuming that they exposed to coal dust of this concentration for 30 years, the risk would exceed the acceptable risk level and measures should be taken. In this study, a practical quantitative approach was proposed to assess the risk of coal-worker's pneumoconiosis caused by coal dust exposure. Based on the results, it showed that as the risk management target, the concentration and exposure duration should be well controlled to reduce the risk of coal-worker's pneumoconiosis. This method could be applied in evaluations of occupational disease hazard in construction projects and help to control and manage the risk of coal-worker's pneumoconiosis.
\end{abstract}

Keywords: Coal dust; Occupational exposure; Pneumoconiosis; Risk assessment; Logistic regression model

\section{Introduction}

Pneumoconiosis is one of the legal occupational diseases in China, which is a systemic disease mainly caused by diffuse pulmonary fibrosis because of long-term inhalation and deposition in the lung of productive dust in occupational activities. Pneumoconiosis is still the most prevalent occupational disease in China, and the annual number of reported pneumoconiosis accounts for more than $80 \%$ of the total number of reported occupational diseases. According to 2015-2016 published national occupational disease reports, a total of 29,180 occupational diseases were reported in 2015 and 26,081 new cases of occupational pneumoconiosis were reported, among which $93.92 \%$ were coal worker pneumoconiosis and silicosis. A total of 31,789 occupational diseases were reported in 2016 , and 27,992 new cases of occupational pneumoconiosis were reported, an increase of 1911 compared with 2015 , among which $95.49 \%$ were coal worker pneumoconiosis and silicosis. Therefore, it is urgently needed to carry out the research and application of occupational exposure risk assessment technology for productive dust such as coal dust, and formulate the best prevention and control measures of pneumoconiosis through risk assessment, so as to provide scientific and technological support for the

* Corresponding author: Deyin Huang (1962-), female, chief physician, research direction is occupational health and risk analysis.

This study was supported by Municipal Key Science and Technology Support Project of Tianjin (No. 13ZCZDSY02300) and Projects funded by the National Health Service (No. 1311400010903). 
implementation of special management of productive dust operations and prevent the occurrence of pneumoconiosis. This paper introduced the method of coal dust occupational exposure risk assessment based on the example of a large petrochemical enterprise thermal power plant coal transportation workshop.

\section{Object and method}

\subsection{Object}

The coal transporters in the coal transportation workshop of the thermal power department of a large petrochemical company were mainly responsible for the discharge, storage and loading of fuel coal. The workers have the characteristics of long dust exposure and high exposure level, and a new case of pneumoconiosis has been reported. Therefore, the company's thermal power plant coal transportation workshop was selected as the research object to evaluate the risk of occupational exposure to coal dust in the coal transportation workshop.

\subsection{Method}

The risk assessment of occupational exposure to coal dust was carried out according to the four-step method of EPA health risk assessment, which was widely used in the world, namely risk identification, exposure assessment, dose-response assessment and risk characterization ${ }^{[1-3]}$. The procedures and contents of risk assessment methods for pneumoconiosis caused by occupational exposure to coal dust were as follows:

(1) Risk identification

In order to identify occupational exposure and potential risk of coal dust in the workplace, relevant data was collected, including occupational history, number of exposed population, gender, age distribution, exposure mode, exposure time, worker protection conditions, free silica content of coal dust, epidemiological data of workers exposed of coal dust.

(2) Exposure assessment

The respirable dust of coal dust was collected, and the scene sampling and laboratory testing were conducted in accordance with current standards related to occupational health.

(3) Dose-response assessment

The logistic model was selected as the dose-response model of coal worker's pneumoconiosis. Population epidemiological data were used to determine the model parameters, and a dose-response model was obtained to evaluate coal worker's pneumoconiosis caused by respiratory coal dust exposure. Non-linear regression of SPSS 19.0.0 was used to fit the dose-response model parameters of coal worker pneumoconiosis caused by occupational exposure to respirable coal dust.

(4) Risk characterization

The dose-response model was used to calculate the risk of coal worker pneumoconiosis with different working age. The risk of coal worker pneumoconiosis caused by the long-term work of coal dust exposed population in this environment was characterized. The relationship between respiratory coal dust concentration, dust duration and incidence of pneumoconiosis was given by computer $\mathrm{R}$ language. The technical route was shown in the figure below.

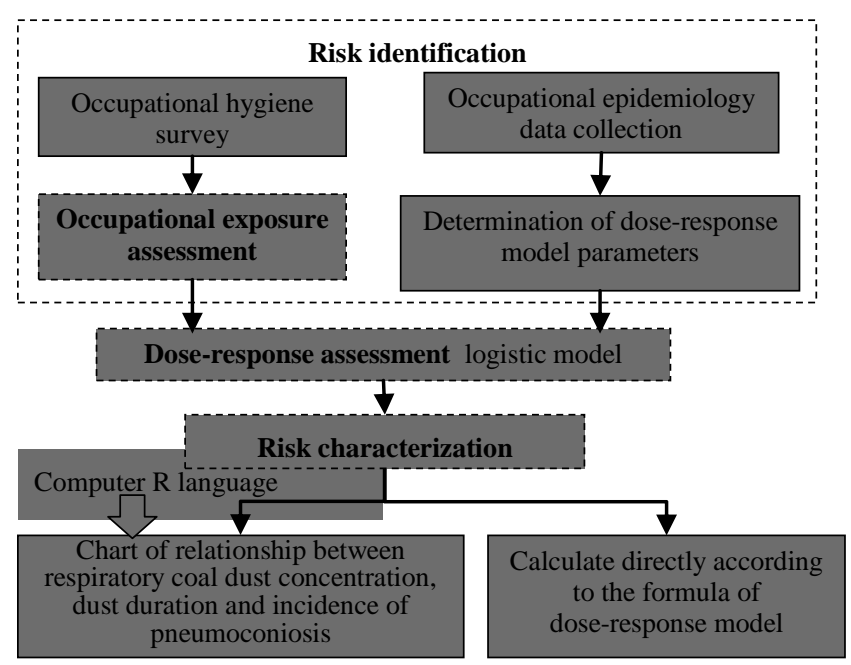

Figure 1 Technical route of occupational disease risk assessment for coal transporters in thermal power plants

\section{Results}

\subsection{Occupational hygiene survey of coal transportation workshop}

The technology operation of coal transportation workshop includes train unloading, coal loading and belt transportation. Storage technology: transportation coal by train - screw coal unloader - coal yard. Transportation technology: ring type coal feeder - vibrating feeder - belt - screen crushing - belt - coal bin. The coal transportation workshop was equipped with comprehensive ventilation facilities, with a total of 93 dust removal facilities, and workers were provided with dustproof masks. 


\subsection{Determination of coal dust exposure level in workplace}

Field sampling and laboratory testing were conducted in accordance with GBZ159 specifications of air sampling for hazardous substances monitoring in the workplace, GBZ/T192.1 determination of dust in the air of workplace-part 1: total dust concentration and GBZ/T192.2 determination of dust in the air of workplace-part 2: respirable dust concentration. According to the exposure data obtained from the occupational health survey, and based on the monitoring data of environmental concentration in the field, the permissible concentration-time weighted average of 8 hours of respiratory coal dust was calculated to evaluate the risk of pneumoconiosis caused by coal dust. The test results of coal dust concentration were shown in table 1.

Table1 The detection results of coal dust in the air of workplace

\begin{tabular}{|c|c|c|c|}
\hline Position & $\begin{array}{c}\text { Coal pipepump } \\
\text { inspector }\end{array}$ & $\begin{array}{c}\text { 2\#,3\#Belt } \\
\text { inspector }\end{array}$ & $\begin{array}{c}\text { 4\#Belt } \\
\text { inspector }\end{array}$ \\
\hline $\begin{array}{c}\text { ResultsTWA } \\
\left(\mathrm{mg} / \mathrm{m}^{3}\right)\end{array}$ & 0.9 & 2.7 & 4.5 \\
\hline
\end{tabular}

\subsection{Dose - response relationship of coal worker pneumoconiosis based on logistic model}

(1) Logistic regression model

The logistic model was selected as the dose-response model of coal worker pneumoconiosis. As a statistical method, the Logistic regression model could objectively and truly present the internal relationship between risk factors and disease risk.

Basic principles of the logistic model: a series of case data was used to fit the logistic regression model, and the model was used to present the relationship between the probability of taking certain values of independent variables and dependent variables. At the same time, all independent variables other than a specific independent variable were controlled to reflect the magnitude of the deterministic effect of that specific independent variable on the probability of taking a specific value of the dependent variable. The risk factors affecting the occupational exposure to coal dust were taken as independent variables and the prevalence rate of coal worker pneumoconiosis as dependent variables. Multiple logistic regression analysis was performed to fit the logistic regression model. The following formula shows the relationship between the probability of a disease $\mathrm{P}$ and the daily dust concentration $a$ and the working age of the dust exposure $b$ :

$$
P=\frac{\exp \left[\beta_{i 0}+\beta_{i 1} \ln (a b)\right]}{1+\exp \left[\beta_{i 0}+\beta_{i 1} \ln (a b)\right]}
$$

where: $P$ - the incidence rate of pneumoconiosis of coal workers with different dust concentration and working age;

$\beta_{i 0}$ - the constant term of logistic regression analysis;

$\beta_{i 1}$ - the regression coefficient of logistic regression analysis;

$a$ - daily dust concentration $\left(\mathrm{mg} / \mathrm{m}^{3}\right)$;

$b$ - the working age of the dust exposure (year).

(2) The parameter fitting of the logistic model

Data of pneumoconiosis epidemiology of coal workers in typical domestic industries were collected. According to the data of occupational exposure level of coal dust and incidence of pneumoconiosis in each investigation instance, the parameter values in the logistic model were fitted. This study mainly collected and adopted the following epidemiological investigation data of coal worker pneumoconiosis ${ }^{[4]}$, as shown in table 2 .

Table 2 Epidemiological survey results of coal workers with pneumoconiosis

\begin{tabular}{|c|c|c|c|c|}
\hline Region & Industry & Type of work & $\begin{array}{l}\text { Cumulative } \\
\text { exposure to dust } \\
\text { ( respiratory } \\
\text { coaldust ) } \\
\left(\mathrm{mg} / \mathrm{m}^{3} \cdot \text { year ) }\right.\end{array}$ & $\begin{array}{l}\text { Cumulative } \\
\text { incidence }\end{array}$ \\
\hline \multirow{20}{*}{$\begin{array}{c}\text { Acoal } \\
\text { mine in } \\
\text { Hebei }\end{array}$} & \multirow{20}{*}{ Coal mine } & \multirow{20}{*}{ coal digger } & 8.73 & 0 \\
\hline & & & 26.18 & 0 \\
\hline & & & 43.63 & 0.0008 \\
\hline & & & 61.08 & 0.002 \\
\hline & & & 78.53 & 0.0036 \\
\hline & & & 95.99 & 0.0125 \\
\hline & & & 113.44 & 0.0156 \\
\hline & & & 130.89 & 0.0207 \\
\hline & & & 148.34 & 0.031 \\
\hline & & & 165.79 & 0.0431 \\
\hline & & & 183.25 & 0.0573 \\
\hline & & & 200.70 & 0.0787 \\
\hline & & & 218.15 & 0.0974 \\
\hline & & & 235.60 & 0.1434 \\
\hline & & & 253.05 & 0.1918 \\
\hline & & & 270.51 & 0.2402 \\
\hline & & & 287.96 & 0.288 \\
\hline & & & 305.41 & 0.3165 \\
\hline & & & 322.86 & 0.3592 \\
\hline & & & 340.31 & 0.3592 \\
\hline \multirow{2}{*}{$\begin{array}{c}\text { Inner } \\
\text { Mongolia }\end{array}$} & \multirow[b]{2}{*}{ Coal mine } & \multirow{2}{*}{$\begin{array}{c}\text { Equipment } \\
\text { operator, belt } \\
\text { driver, etc }\end{array}$} & 61.08 & 0.0194 \\
\hline & & & 78.53 & 0.0441 \\
\hline $\begin{array}{c}\text { The } \\
\text { Yangtze } \\
\text { river north } \\
\text { shore }\end{array}$ & $\begin{array}{c}\text { Port } \\
\text { transportation }\end{array}$ & Stevedore & 52.36 & 0.1781 \\
\hline \multirow{2}{*}{ Shanxi } & \multirow{2}{*}{ Coal mine } & \multirow{2}{*}{$\begin{array}{l}\text { Coal mine } \\
\text { workers }\end{array}$} & 16.29 & 0.01 \\
\hline & & & 13.04 & 0.005 \\
\hline
\end{tabular}


Based on the dose-response relationship between occupational exposure accumulation of respiratory coal dust and incidence of pneumoconiosis in table 2, SPSS 19.0.0 logistic nonlinear regression was used to fit the collected data of pneumoconiosis epidemiology. The parameter values in the logistic model were obtained: $\beta_{\mathrm{i} 0}=-20.890, \beta_{\mathrm{i} 1}=3.508, \mathrm{R}^{2}=0.898$. By testing, it could be considered that the product of dust concentration and working age of the dust exposure, namely, the accumulated dust quantity was related to the incidence rate. The dose-response model of coal worker's pneumoconiosis is:

$$
P=\frac{\exp [-20.890+3.508 \ln (a b)]}{1+\exp [-20.890+3.508 \ln (a b)]}
$$

where: $a$-respirable coal dust concentration, namely permissible concentration-time weighted average of 8 hours $\left(\mathrm{mg} / \mathrm{m}^{3}\right)$

$b$-the working age of the dust exposure (year)

\subsection{Risk characterization results}

(1) Direct calculation

Using the logistic regression model established in the dose-response assessment, the actual exposure level data of the workers were substituted into the dose-response model established above to calculate the risk value of coal worker pneumoconiosis. The coal dust exposure at each position and the predicted risk of coal worker pneumoconiosis were shown in table 3 .
Table 3 Coal dust exposure and risk of coal worker pneumoconiosis at each position

\begin{tabular}{|c|c|c|c|c|c|}
\hline \multirow{2}{*}{ Position } & $\begin{array}{c}\text { Concentration } \\
\text { of respirable } \\
\text { dust ( TWA }) \\
\text { mg/m }\end{array}$ & \multicolumn{3}{|c|}{$\begin{array}{c}\text { Risk of coal worker pneumoconiosis with } \\
\text { different working ages }\end{array}$} \\
\cline { 3 - 6 } & 5 years & 10 years & 20 years & 30 years \\
\hline $\begin{array}{c}\text { Coal pipepump } \\
\text { inspector }\end{array}$ & 0.9 & $1.66 \times 10^{-7}$ & $1.88 \times 10^{-6}$ & $2.14 \times 10^{-5}$ & $8.89 \times 10^{-5}$ \\
\hline $\begin{array}{c}\text { 2\#,3\#Belt } \\
\text { inspector }\end{array}$ & 2.7 & $7.81 \times 10^{-6}$ & $8.89 \times 10^{-5}$ & $1.01 \times 10^{-3}$ & $4.18 \times 10^{-3}$ \\
\hline 4\#Beltinspector & 4.5 & $4.69 \times 10^{-5}$ & $5.33 \times 10^{-4}$ & $6.03 \times 10^{-3}$ & $2.45 \times 10^{-2}$ \\
\hline
\end{tabular}

(2) Relationship between respiratory coal dust concentration, dust duration and incidence of pneumoconiosis based on computer $\mathrm{R}$ language

In order to improve the practicability of the risk assessment method in this study and facilitate the calculation of the risk of pneumoconiosis caused by occupational exposure to respirable coal dust, a zoom table was given for the relationship between the dust permissible concentration-time weighted average of 8 hours, the working age of the dust exposure and the incidence rate of pneumoconiosis of coal workers. The incidence of pneumoconiosis of coal workers corresponding to different dust concentration and 5, 10, 20 and 30 years of working age could be found in the table. Taking the 20-year working age of coal conveyors as an example, the risk prediction of coal worker pneumoconiosis exposed to different respirable coal dust concentration was shown in table 4.

Table 4 Prediction of the risk of coal worker pneumoconiosis with 20 years of dust exposure working age under different concentrations of respirable coal dust

\begin{tabular}{|c|c|c|c|c|c|c|c|c|c|}
\hline $\begin{array}{c}\text { Concentration } \\
\left(\mathrm{mg} / \mathrm{m}^{3}\right)\end{array}$ & Risk & $\begin{array}{c}\text { Concentration } \\
\left(\mathrm{mg} / \mathrm{m}^{3}\right)\end{array}$ & Risk & $\begin{array}{c}\text { Concentration } \\
\left(\mathrm{mg} / \mathrm{m}^{3}\right)\end{array}$ & Risk & $\begin{array}{c}\text { Concentration } \\
\left(\mathrm{mg} / \mathrm{m}^{3}\right)\end{array}$ & Risk & $\begin{array}{c}\text { Concentration } \\
\left(\mathrm{mg} / \mathrm{m}^{3}\right)\end{array}$ & Risk \\
\hline 0.5 & $2.73 \times 10^{6}$ & 10.5 & $1.06 \times 10^{-1}$ & 20.5 & $5.53 \times 10^{-1}$ & 30.5 & $8.33 \times 10^{-1}$ & 40.5 & $9.31 \times 10^{-1}$ \\
\hline 1 & $3.10 \times 10^{5}$ & 11 & $1.22 \times 10^{-1}$ & 21 & $5.74 \times 10^{-1}$ & 31 & $8.41 \times 10^{-1}$ & 41 & $9.34 \times 10^{-1}$ \\
\hline 1.5 & $1.29 \times 10^{4}$ & 11.5 & $1.40 \times 10^{-1}$ & 21.5 & $5.94 \times 10^{-1}$ & 31.5 & $8.48 \times 10^{-1}$ & 41.5 & $9.36 \times 10^{-1}$ \\
\hline 2 & $3.53 \times 10^{4}$ & 12 & $1.59 \times 10^{-1}$ & 22 & $6.14 \times 10^{-1}$ & 32 & $8.55 \times 10^{-1}$ & 42 & $9.39 \times 10^{-1}$ \\
\hline 2.5 & $7.71 \times 10^{4}$ & 12.5 & $1.79 \times 10^{-1}$ & 22.5 & $6.32 \times 10^{-1}$ & 32.5 & $8.62 \times 10^{-1}$ & 42.5 & $9.41 \times 10^{-1}$ \\
\hline 3 & $1.46 \times 10^{-3}$ & 13 & $2.01 \times 10^{-1}$ & 23 & $6.50 \times 10^{-1}$ & 33 & $8.68 \times 10^{-1}$ & 43 & $9.43 \times 10^{-1}$ \\
\hline 3.5 & $2.51 \times 10^{-3}$ & 13.5 & $2.23 \times 10^{-1}$ & 23.5 & $6.67 \times 10^{-1}$ & 33.5 & $8.74 \times 10^{-1}$ & 43.5 & $9.46 \times 10^{-1}$ \\
\hline 4 & $4.00 \times 10^{-3}$ & 14 & $2.45 \times 10^{-1}$ & 24 & $6.83 \times 10^{-1}$ & 34 & $8.80 \times 10^{-1}$ & 44 & $9.48 \times 10^{-1}$ \\
\hline 4.5 & $6.03 \times 10^{-3}$ & 14.5 & $2.69 \times 10^{-1}$ & 24.5 & $6.98 \times 10^{-1}$ & 34.5 & $8.85 \times 10^{-1}$ & 44.5 & $9.49 \times 10^{-1}$ \\
\hline 5 & $8.71 \times 10^{-3}$ & 15 & $2.93 \times 10^{-1}$ & 25 & $7.13 \times 10^{-1}$ & 35 & $8.90 \times 10^{-1}$ & 45 & $9.51 \times 10^{-1}$ \\
\hline 5.5 & $1.21 \times 10^{-2}$ & 15.5 & $3.17 \times 10^{-1}$ & 25.5 & $7.27 \times 10^{-1}$ & 35.5 & $8.95 \times 10^{-1}$ & 45.5 & $9.53 \times 10^{-1}$ \\
\hline 6 & $1.64 \times 10^{-2}$ & 16 & $3.42 \times 10^{-1}$ & 26 & $7.40 \times 10^{-1}$ & 36 & $8.99 \times 10^{-1}$ & 46 & $9.55 \times 10^{-1}$ \\
\hline 6.5 & $2.16 \times 10^{-2}$ & 16.5 & $3.67 \times 10^{-1}$ & 26.5 & $7.53 \times 10^{-1}$ & 36.5 & $9.04 \times 10^{-1}$ & 46.5 & $9.56 \times 10^{-1}$ \\
\hline 7 & $2.78 \times 10^{-2}$ & 17 & $3.91 \times 10^{-1}$ & 27 & $7.65 \times 10^{-1}$ & 37 & $9.08 \times 10^{-1}$ & 47 & $9.58 \times 10^{-1}$ \\
\hline 7.5 & $3.51 \times 10^{-2}$ & 17.5 & $4.16 \times 10^{-1}$ & 27.5 & $7.76 \times 10^{-1}$ & 37.5 & $9.12 \times 10^{-1}$ & 47.5 & $9.59 \times 10^{-1}$ \\
\hline 8 & $4.37 \times 10^{-2}$ & 18 & $4.40 \times 10^{-1}$ & 28 & $7.87 \times 10^{-1}$ & 38 & $9.15 \times 10^{-1}$ & 48 & $9.61 \times 10^{-1}$ \\
\hline 8.5 & $5.35 \times 10^{-2}$ & 18.5 & $4.64 \times 10^{-1}$ & 28.5 & $7.97 \times 10^{-1}$ & 38.5 & $9.19 \times 10^{-1}$ & 48.5 & $9.62 \times 10^{-1}$ \\
\hline 9 & $6.46 \times 10^{-2}$ & 19 & $4.87 \times 10^{-1}$ & 29 & $8.07 \times 10^{-1}$ & 39 & $9.22 \times 10^{-1}$ & 49 & $9.63 \times 10^{-1}$ \\
\hline 9.5 & $7.70 \times 10^{-2}$ & 19.5 & $5.10 \times 10^{-1}$ & 29.5 & $8.16 \times 10^{-1}$ & 39.5 & $9.25 \times 10^{-1}$ & 49.5 & $9.65 \times 10^{-1}$ \\
\hline 10 & $9.08 \times 10^{-2}$ & 20 & $5.32 \times 10^{-1}$ & 30 & $8.25 \times 10^{-1}$ & 40 & $9.28 \times 10^{-1}$ & 50 & $9.66 \times 10^{-1}$ \\
\hline
\end{tabular}


In addition, the relationship between pneumoconiosis incidence and dust concentration of coal workers with different working age could be plotted according to the risk prediction zoom table. Take the 20 -year working age of coal conveyer for example, see figure 2 .

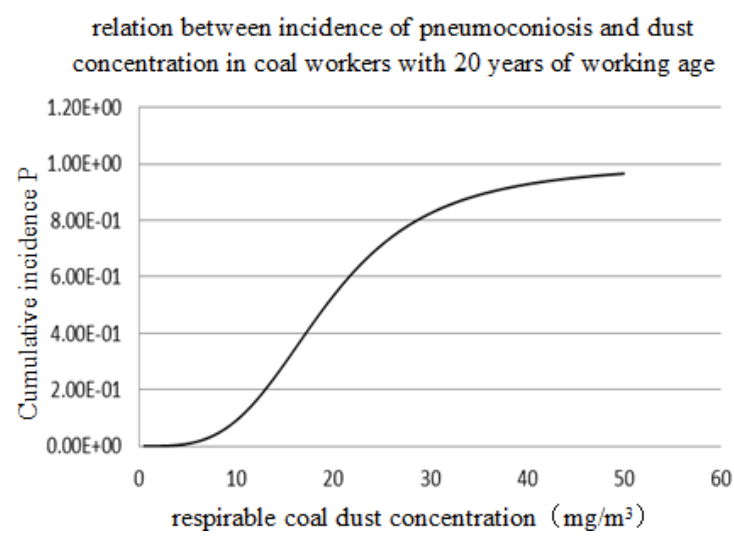

Figure 2 Relation between incidence of pneumoconiosis and dust concentration in coal workers with 20 years of working age

\section{Risk control countermeasures and suggestions}

As can be seen from the results of risk characterization, based on the working age of 30 years, it was assumed that workers do not wear dust masks, and that the risk of exposure to coal dust was higher than $1 \times 10^{-4}$ level for belt inspectors $2 \#, 3 \#$ and $4 \#$, and measures should be taken to reduce the risk. In view of the high risk of occupational hazards existing in the occupational exposure of coal dust, the engineering technical control measures should be firstly improved according to the priority of risk, and the following problems existing in the current occupational-disease-prevention facilities should be improved.

(1) The excessive coal dust in the existing post mainly refers to the loose coal dust when the belt machine drops the coal. It was suggested to consider setting a better sealed dust cover at the coal drop place, and to form a micro negative pressure inside the cover when the coal falls, so as to reduce the loose coal dust. Carefully analyze the reason why existing dust removal system cannot effectively prevent dust, further clarify the form, location and quantity of the dust removal system, and ensure that the coal dust concentration must measure up to the standards.

(2) Reduce the transfer drop of coal as much as possible. It must be ensure that the automatic dust remover and spray dust removal facilities set at each transfer point of belt conveyor can meet the requirements of dust prevention with the long-term use.

(3) Strengthen the tightness of the pulverizing system of the workshop, prevent the leakage of coal powder and reduce the impact on the working environment.

(4) Strengthen wet operation with process permission. The atomizing sprinkler facilities, corresponding supporting water pipes and gathering flume should be added to ensure the implementation of wet operation and reduce dust.

(5) The wind speed of the dust collector should be increased, in order to improve the efficiency of dust collection and make the concentration of coal dust in the air of workplace measure up to the standards.

In addition, strict occupational health management measures should be adopted to strengthen personal protection of workers, equip workers with dust masks, and guide and supervise workers to wear them correctly; Strengthen the training and education for operators to use and maintain respiratory protective equipment, and require operators to strictly observe operating procedures; Strengthen the daily maintenance and overhaul of the protection facilities to keep them in normal operation and good ventilation and dust removal effect. Regular occupational health inspections and routine monitoring of coal dust were needed to control and reduce risks.

\section{Conclusions and discussions}

By using logistic regression model of the nonlinear regression analysis, this paper set up the occupational exposure risk assessment method of coal dust on the basis of conventional epidemiological data, through the main factors of coal workers pneumoconiosis respirable coal dust concentration and the working age of the dust exposure. This method could predict the coal workers pneumoconiosis incidence probability, in order to evaluate occupational disease hazard risk of coal workplace. Risk characterization adopted computer $\mathrm{R}$ language to conduct a visual study on the relationship respiratory coal dust concentration, dust duration and incidence of pneumoconiosis, and conduct a zoom table of the results of risk characterization, which was convenient for occupational health workers to use and consult, so that the research results have strong practicability and operability. 
By case study, it was proved that the risk assessment method of coal dust occupational exposure proposed in this study could be applied to the occupational hazard assessment of construction projects, coal dust occupational exposure assessment and risk analysis, as well as the daily risk management of occupational hazards of employers and the management of high-risk occupational diseases such as coal dust. This was of great significance to optimize working conditions, prevent and control occupational diseases and reduce the risk of occupational diseases.

\section{References}

[1] Li Min-yan, Huang De-yin, Liu Mao. Mcsim-based occupational health risk assessment on benzene[J]. Journal of Risk Analysis and Crisis Response, 2013, 3(3):135-145.

[2] Zhang Qian, Huang De-yin, Liu Mao. Internal exposure simulation based on exposure related dose estimating model[J]. Journal of Risk Analysis and Crisis Response, 2013,3(4):175-184.

[3] Zhang Q, Huang D Y, Liu M. Study on risk evaluation based on occupational exposure evaluation and carcinogenic risk simulation[J]. Journal of Risk Analysis and Crisis Response, 2014, 4(4):228-232.

[4] Wang Y J, Zhang J, Yin X Y. Development trend of incidence of pneumoconiosis in Tianjin[J]. Chinese Journal of Industrial Hygiene And Occupational Diseases, 2001,1:70-71.

[5] Hua Zheng-bin, Sun Zhi-qian, Qin Tian-bang. Dose-response relationship between cumulative dust exposure and pneumoconiosis risk among workers exposed to dust in a coal mine in Hebei[J]. Journal of Labour Medicine, 2015,32(1):1-6.

[6] Wang Xin-Ping, Liu Tie-Min. Study on the dose-response relationship between respirable coal dust and pneumoconiosis[J]. Journal of Safety Science and Technology, 2007,3(2):70-73.

[7] Cai Li-Qun Wei Zhe. Study on the developmental regularity of coal workers' pneumoconiosis using logistic regression model[J]. Chinese Journal of Industrial Hygiene and Occupational Diseases, 1990,8(4):223-226.

[8] Pei Jun-Xue, Li Wan-Peng. The relationship between coal dust exposure and pneumoconiosis [J]. Inner Mongolia Coal Economy, 2001,4:12-14.

[9] Hu Jian-an, Chen An-Chao, Li Pei-Shan, et al. Dose-response relationship between respirable dust and pneumoconiosis in coal mine[J]. Chinese Journal of Industrial Medicine, 1992,5(2):66-69 